\title{
Influence of Carotid Siphon Anatomy on Brain Aneurysm Presentation
}

\author{
(D)E. Waihrich, DP. Clavel, (D) G.A.C. Mendes, (D) C. Iosif, DI. Moraes Kessler, and (D) C. Mounayer
}

\begin{abstract}
BACKGROUND AND PURPOSE: Intracranial aneurysm is a devastating disease of complex etiology that is not fully understood. The purpose of this study was to assess the implications of carotid siphon anatomy for the formation and development of intracranial aneurysms.
\end{abstract}

\begin{abstract}
MATERIALS AND METHODS: Between January 2007 and May 2015, lateral view digital subtraction angiographic images of 692 consecutive patients with intracranial aneurysms treated in our department of interventional neuroradiology were reviewed and had their angles measured. Data on the location, presentation, and size of the lesions were collected and evaluated by multivariate analysis in relation to the measured angles.
\end{abstract}

RESULTS: Of 692 aneurysms, 225 (32.51\%) ruptured and 467 (67.49\%) unruptured, 218 (31.50\%) were in the carotid siphon and 474 (68.50\%) were distal to the siphon, and the mean aneurysm size was $7.99 \pm 6.95 \mathrm{~mm}$. Multivariate analysis showed an association between angles of $>15.40^{\circ}$ and rupture $(P=.005)$, postsiphon location $(P=.034)$, and aneurysm size of $>1.001 \mathrm{~mm}(P=.015)$. Multivariate analysis also showed that every 1-year increase in patient age produced an increase of $1.002 \mathrm{~mm}$ in aneurysm size $(P=.015)$.

CONCLUSIONS: There was a significant independent direct relation of greater anterior knee angle with intracranial aneurysms located distal to the carotid siphon, larger aneurysms, and greater risk of rupture. These findings may be associated with the hemodynamic interactions of blood flow and the curvature of the carotid siphon.

l: ntracranial aneurysms affect approximately $6 \%-10 \%$ of the world population. Fortunately, only $0.05 \%$ of patients progress to rupture, but they face a devastating consequence, subarachnoid hemorrhage, with mortality rates ranging from $56 \%$ to $80 \%$. $^{1,2}$

Several factors are related to the formation, development, and rupture of intracranial aneurysms. Among these, the hemodynamic interactions of blood flow and vessel wall have received special attention in recent years. The balance between hemodynamic stress secondary to blood flow in the water hammer pulse and parallel shear stress caused by blood viscosity and friction between blood and the arterial wall appears to be related to the origin and development of aneurysms. That hemodynamic contribution can be exemplified by the preferred location of aneurysms at arterial bifurcations and curvatures. ${ }^{3-6}$ Thus, the carotid

Received February 8, 2017; accepted after revision May 4.

From the Department of Interventional Neuroradiology (E.W., P.C., G.A.C.M., C.I., C.M.), Dupuytren University Hospital, Limoges, France; and Department of Neurosurgery (E.W., I.M.K.), Universidade de Brasília, Brasília, DF, Brazil.

Please address correspondence to Eduardo Siqueira Waihrich, MD, MSc, SHIS QI 15, Centro Médico Brasília - Brasília - DF 71635-550; e-mail: eduwaihrich@gmail.com

http://dx.doi.org/10.3174/ajnr.A5285 siphon is of particular importance because it is a tortuous vessel segment with sharp bends through which blood enters the anterior cerebral circulation. ${ }^{7-9}$

The aim of this study was to investigate the morphologic characteristics of the carotid siphon and their possible association with the formation, development, and occurrence of intracranial aneurysms at this site.

\section{MATERIALS AND METHODS}

The study was approved by the ethics committee of our institution, Dupuytren University Hospital, and written informed consent was obtained from each patient. Data were retrospectively and prospectively collected for all patients with intracranial aneurysms who underwent endovascular treatment between January 2007 and May 2015. Patients with posterior circulation aneurysms, poor-quality digital subtraction angiographic images preventing angle measurement, incomplete documentation, or conditions (medical or other) precluding follow-up were excluded.

Demographic data (age and sex), type of aneurysm, and angiographic features were evaluated. The following angiographic features were considered for analysis: aneurysm size (maximum aneurysm sac diameter), location of the aneurysm in the carotid 

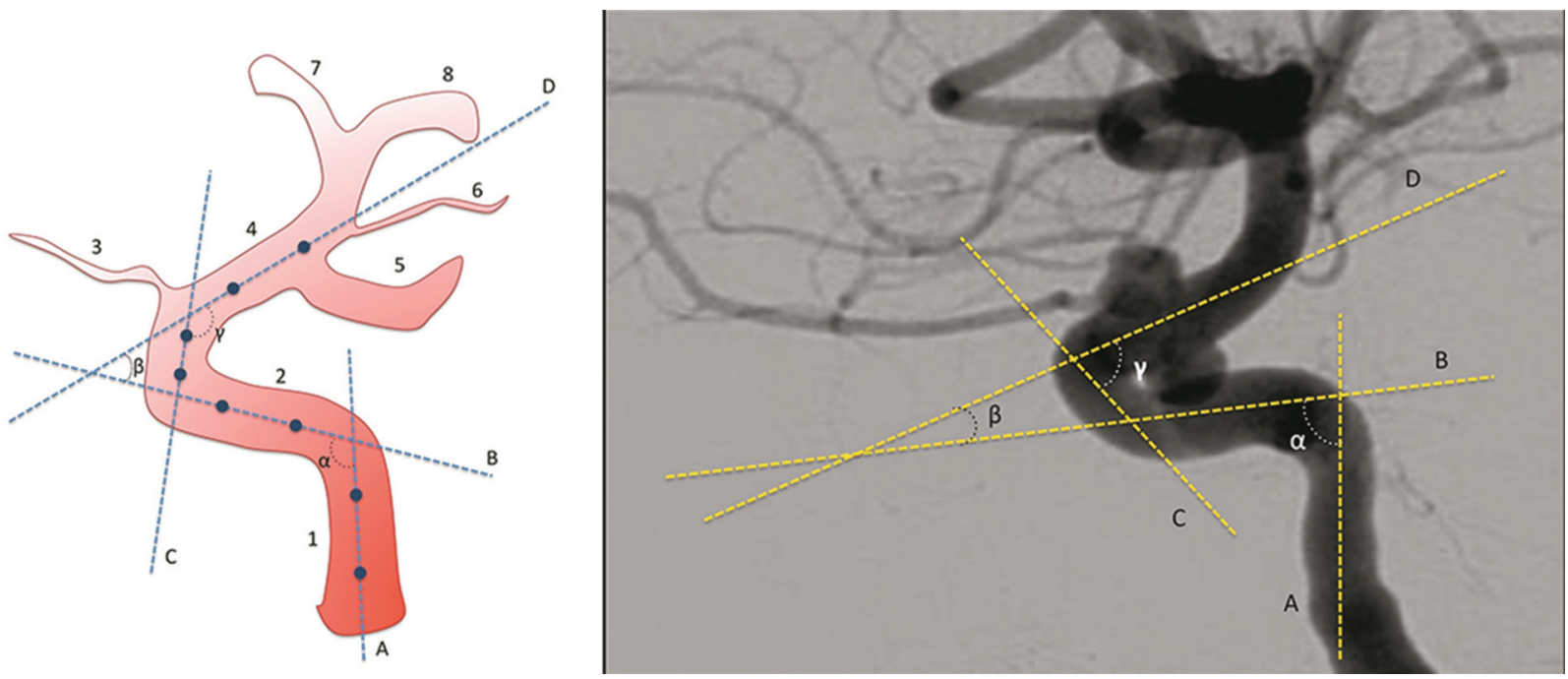

FIG 1. Technique for measurement of carotid siphon angles. On the left, an illustration of a carotid siphon with lines traced to cross the midpoints of the diameters of the straight segments of the siphon. On the right, an example of an actual measurement process. A, Line through the vertical petrous segment. B, Line through the horizontal cavernous segment. C, Line through the vertical cavernous segment. D, Line through the supraclinoid segment. $\alpha$, Posterior bend angle. $\beta$, Anterior bend angle. $\gamma$, Anterosuperior bend angle. 1, Ascending petrous segment. 2 , Intracavernous segment. 3, Ophthalmic artery. 4, Supraclinoid segment. 5, Posterior communicating artery. 6, Anterior choroidal artery. 7, Anterior cerebral artery. 8, Middle cerebral artery.

siphon (cavernous or supraclinoid segment) or distal to it, and angle of the posterior and anterior knees of the carotid siphon.

Pretreatment intraoperative DSA images obtained after contrast injection into the affected carotid artery (lateral view with the external acoustic meatus at the same level) were assessed by 2 blinded neuroradiologists. Carotid siphon angles were measured at the intersection of 2 lines traced through the midpoints of the diameters of each straight segment of the siphon (Fig 1). ${ }^{10}$ If the lines of the cavernous and supraclinoid segments crossed posterior to the siphon due to its tortuosity, the angle of the anterior knee of the carotid siphon received a negative value. ${ }^{10}$

\section{Statistical Analysis}

Multivariate Poisson and logistic regression and multiple linear regression models were used to explore the relationship between demographic and angiographic data with respect to the measured angles. ${ }^{11-13}$ Categoric independent variables were divided according to their classification, and continuous independent variables were divided with the median as the cutoff value, as long as a linearity correlation was not observed, as follows: sex (male or female), age ( 55 years or younger or 55 years and older), aneurysm rupture (yes or no), location (cavernous segment, supraclinoid segment, or distal to the carotid siphon), and size $(\leq 5 \mathrm{~mm}$, 6-10 $\mathrm{mm}, 10-25 \mathrm{~mm}$, or $>25 \mathrm{~mm})$, anterior angle $\left(\leq 15.40^{\circ}\right.$ or $\left.>15.40^{\circ}\right)$, and posterior angle $\left(\leq 88.15^{\circ}\right.$ or $\left.>88.15^{\circ}\right)$. The cavernous location begins at the petrolingual ligament and extends to the proximal dural ring, which is formed by the medial and inferior periosteum of the anterior clinoid process; the supraclinoid location extended until carotid bifurcation and the postsiphon location comprised the bifurcation onwards. We decided to use the median as a cutoff value to have 2 groups with similar numbers of patients for multivariate analysis. In analysis between the angles and a single other numeric variable, the variables were also analyzed as continuous whenever feasible. Bivariate and multi- variate analyses were performed, and in both, prevalence ratios and their respective $95 \%$ confidence intervals were calculated. The bivariate analysis was used to examine the association between each independent variable and the occurrence of ruptured intracranial aneurysms, followed by multivariate analysis. Statistical analysis was performed with SPSS, Version 22.0 (IBM, Armonk, New York). $P<.05$ was considered significant.

\section{RESULTS}

Between January 2007 and May 2015, 703 patients with a diagnosis of intracranial aneurysm were treated at the department of interventional neuroradiology of the institution. Of these, 640 patients were eligible and agreed to participate in the study, for a total of 692 intracranial aneurysms.

Of 692 aneurysms, 457 occurred in women $(66.04 \%)$ and 235 in men $(33.96 \%)$. The mean patient age was $54.75 \pm 13.13$ years (men, $54.70 \pm 13.16$ years; women, $54.66 \pm 13.13$ years). There were $225(32.51 \%)$ ruptured aneurysms and 467 (67.49\%) unruptured aneurysms. Regarding aneurysm location, 218 (31.50\%) were in the carotid siphon and $474(68.50 \%)$ were distal to the siphon. Mean aneurysm size was $7.99 \pm 6.95 \mathrm{~mm}$ (Table 1).

\section{Aneurysm Rupture}

The bivariate analysis showed a statistically significant association between a ruptured intracranial aneurysm and an anterior knee angle of $>15.40^{\circ}$ (prevalence ratio $=1.45 ; 95 \%$ CI, 1.16-1.80). Subsequently, sex, age, location, size, and posterior and anterior knee angles were included in the Poisson regression model, but only an anterior knee angle of $>15.40^{\circ}$ showed a significant association with ruptured intracranial aneurysms. After we adjusted for the variables mentioned above, there was an increased association (prevalence ratio $=1.36$; 95\% CI, 1.09-1.69) — that is, patients with aneurysms and an anterior knee angle of $>15.40^{\circ}$ showed a $36 \%$ higher prevalence of rupture than patients with an anterior knee angle of $\leq 15.40^{\circ}$ (Table 2). 
In the stratified subgroup analysis by location, only aneurysms located in the anterior communicating artery showed a greater statistical risk of rupture in patients with an anterior angle of $>15.40^{\circ}$ $(P=.049)$. The risk of rupture was $84 \%$ greater in patients with an anterior angle of $>15.40^{\circ}$ than in those with an angle of $\leq 15.40^{\circ}$ at this location (Table 3).

Table 1: Epidemiologic data

\begin{tabular}{|c|c|}
\hline Variables & \\
\hline $\begin{array}{l}\text { Total No. of IAs (\%) } \\
\text { Mean age (yr) }\end{array}$ & $\begin{array}{c}692(100) \\
(54.75 \pm 13.13)\end{array}$ \\
\hline \multicolumn{2}{|l|}{ Sex } \\
\hline Women with IAs (No.) (\%) & $457(66.04)$ \\
\hline Mean age (yr) & $(54.66 \pm 13.13)$ \\
\hline Men with IAs (No.) (\%) & $235(33.96)$ \\
\hline Mean age (yr) & $(54.70 \pm 13.16)$ \\
\hline \multicolumn{2}{|l|}{ Rupture (No.) (\%) } \\
\hline Ruptured IAs & $225(32.51)$ \\
\hline Unruptured IAs & $467(67.49)$ \\
\hline \multicolumn{2}{|l|}{ IA location (No.) (\%) } \\
\hline Siphon & $218(31.50)$ \\
\hline Cavernous segment & $45(6.50)$ \\
\hline Supraclinoid segment & $173(25.00)$ \\
\hline Ophthalmic & $67(9.68)$ \\
\hline PcomA & $96(13.87)$ \\
\hline Ant. chor & $10(1.45)$ \\
\hline Postsiphon (No.) (\%) & $474(68.50)$ \\
\hline Bifurcation & $35(5.06)$ \\
\hline MCA & $237(34.25)$ \\
\hline AcomA & $170(24.57)$ \\
\hline $\mathrm{ACA} /$ pericallosal & $32(4.62)$ \\
\hline \multicolumn{2}{|l|}{ IA size (No.) (\%) } \\
\hline$\leq 5 \mathrm{~mm}$ & 334 (48.27) \\
\hline 6-10 mm & $233(33.67)$ \\
\hline $11-25 \mathrm{~mm}$ & $97(14.02)$ \\
\hline$>25 \mathrm{~mm}$ & $28(4.05)$ \\
\hline
\end{tabular}

Note:-IA indicates intracranial aneurysm; PcomA, posterior communicating segment; Ant. chor, anterior choroidal segment; ACA, anterior cerebral artery; AcomA, anterior communicating artery.

Table 2: Distribution of the study variables and association with aneurysm rupture based on crude and adjusted prevalence ratios according to the Poisson regression model with robust variance and their respective $95 \% \mathrm{Cls}$

\begin{tabular}{|c|c|c|c|c|}
\hline \multirow[b]{2}{*}{ Variables } & \multicolumn{2}{|c|}{ Crude PR } & \multicolumn{2}{|c|}{ Adjusted PR } \\
\hline & PR $(95 \% \mathrm{Cl})$ & $P$ Value & PR $(95 \% \mathrm{Cl})$ & $P$ Value \\
\hline Sex & & .428 & & .938 \\
\hline Female & 1 & - & 1 & - \\
\hline Male & $1.09(0.88-1.37)$ & .428 & $1.01(0.81-1.25)$ & .938 \\
\hline Age & & .413 & & .640 \\
\hline 55 yr or younger & $1.09(0.88-1.36)$ & .413 & 1.05 (0.83-1.31) & .640 \\
\hline Older than $55 \mathrm{yr}$ & 1 & - & 1 & - \\
\hline Aneurysm location & & .009 & & .022 \\
\hline Postsiphon & $1.18(0.91-1.52)$ & .208 & $1.11(0.86-1.44)$ & .416 \\
\hline Supraclinoid segment & 1 & - & 1 & - \\
\hline Aneurysm size & & .134 & & .445 \\
\hline$\leq 5 \mathrm{~mm}$ & 3.92 (1.04-14.81) & .044 & $2.18(0.57-8.27)$ & .252 \\
\hline 6-10 mm & $3.49(0.92-13.27)$ & .066 & $1.96(0.51-7.52)$ & .326 \\
\hline $11-25$ mm & $3.20(0.83-12.42)$ & .092 & $1.91(0.49-7.40)$ & .350 \\
\hline$>25 \mathrm{~mm}$ & 1 & - & 1 & - \\
\hline Anterior knee angle & & .001 & & .005 \\
\hline$\leq 15.40^{\circ}$ & 1 & - & 1 & - \\
\hline$>15.40^{\circ}$ & 1.45 (1.16-1.80) & .001 & $1.36(1.09-1.69)$ & .005 \\
\hline Posterior knee angle & & .685 & & .773 \\
\hline$\leq 88.15^{\circ}$ & 1 & - & 1 & - \\
\hline$>88.15^{\circ}$ & $1.05(0.84-1.30)$ & .685 & $1.03(0.84-1.27)$ & .773 \\
\hline
\end{tabular}

Note:-PR indicates prevalence ratio.

\section{Aneurysm Location}

The bivariate analysis showed a statistically significant association between postsiphon location of the intracranial aneurysm and the following variables: male sex (odds ratio $=2.38$; 95\% CI, 1.59 3.56 ), age 55 years or younger ( $\mathrm{OR}=1.46 ; 95 \% \mathrm{CI}, 1.03-2.06)$, size $\leq 5 \mathrm{~mm}(\mathrm{OR}=1.92 ; 95 \% \mathrm{CI}, 1.20-3.06)$, size $6-10 \mathrm{~mm}$ $(\mathrm{OR}=2.09 ; 95 \% \mathrm{CI}, 1.27-3.45)$, and an anterior knee angle of $>15.40^{\circ}(\mathrm{OR}=1.55 ; 95 \% \mathrm{CI}, 1.09-2.20)$. For the multivariate analysis, sex, age, rupture, size, and anterior and posterior knee angles were included in the logistic regression model.

When the postsiphon and siphon locations were compared, being male and having an anterior knee angle of $>15.40^{\circ}$ were significantly associated with the postsiphon location. Regarding sex, after we adjusted for the variables mentioned above, there was a decreased association ( $\mathrm{OR}=2.23$; 95\% CI, 1.48-3.37) —that is, men were 2.23 times more likely to have an aneurysm located distal to the siphon than women. Regarding the anterior knee angle, after we adjusted for the variables mentioned above, there was an increased association $(\mathrm{OR}=1.48 ; 95 \% \mathrm{CI}, 1.03-2.13)$ that is, patients with an anterior knee angle of $>15.40^{\circ}$ had a $48 \%$ greater chance of having an aneurysm in the postsiphon location than patients with an anterior knee angle of $\leq 15.40^{\circ}$.

When the cavernous and supraclinoid segment locations were compared, only aneurysms of $<25 \mathrm{~mm}$ were associated with the cavernous segment. After adjustment for the variables mentioned above and comparison with aneurysms of $>25 \mathrm{~mm}$, aneurysms of $\leq 5 \mathrm{~mm}$ had a $92 \%$ lower chance $(\mathrm{OR}=0.08 ; 95 \% \mathrm{CI}, 0.02-0.28)$, aneurysms of $6-10 \mathrm{~mm}$ had a $91 \%$ lower chance $(\mathrm{OR}=0.09 ; 95 \%$ CI, $0.03-0.35)$, and aneurysms of $11-25 \mathrm{~mm}$ had an $88 \%$ lower chance $(\mathrm{OR}=0.12$; 95\% CI, 0.03-0.45) of occurring in the cavernous segment (Table 4).

\section{Aneurysm Size}

Multiple linear regression analysis showed that the following variables were predictors significantly associated with aneurysm size: 1) supraclinoid versus postsiphon location: patients with aneurysms located in the supraclinoid segment had mean aneurysm size values 1.06 $\mathrm{mm}$ higher than those with aneurysms in the postsiphon location $(P=.016) ; 2)$ cavernous versus supraclinoid location: patients with aneurysms located in the cavernous segment had mean aneurysm size values $1.24 \mathrm{~mm}$ higher than those with aneurysms located in the supraclinoid segment $(P<.001)$; 3$)$ aneurysm rupture: patients with unruptured aneurysms had mean aneurysm size values $1.05 \mathrm{~mm}$ higher than those with ruptured aneurysms $(P=.026) ; 4)$ anterior knee angle: every $1^{\circ}$ increase in the anterior angle produced an increase of $1.001 \mathrm{~mm}$ in aneurysm size $(P=.015)$; and 5$)$ age: every 1-year increase in age produced an average increase of $1.002 \mathrm{~mm}$ in aneurysm size $(P=.003)$ (Table 5). 


\section{DISCUSSION}

Ruptured intracranial aneurysms remain one of the neurosurgical diseases with the highest morbidity and mortality. Despite advances in the knowledge of causes and progression of aneurysms, an understanding of the etiologic mechanisms underlying this disorder is still a challenge in modern neurosurgery.

Recently, hemodynamic studies of the interaction of blood flow and the endothelial wall have received increased attention as an important element in the origin, development, and rupture of intracranial aneurysms. ${ }^{14-16}$ Thus, studies of interactions at the level of the carotid siphon are particularly important because of the anatomic peculiarities of this region and approximately onethird of all intracranial aneurysms being located at this site. ${ }^{1,7,8}$

Studies such as those conducted by Lin et al, ${ }^{8}$ Bogunović et al, ${ }^{9}$ and Takeuchi and Karino ${ }^{3}$ have shown that vessels anatomically characterized by sharper bends are associated with higher wall

\begin{tabular}{|c|c|c|c|c|}
\hline $\begin{array}{l}\text { Location/ } \\
\text { Angle }\end{array}$ & $\begin{array}{c}\text { Unruptured } \\
(\%)\end{array}$ & $\begin{array}{c}\text { Ruptured } \\
(\%)\end{array}$ & $\begin{array}{c}P \\
\text { Value }\end{array}$ & $\begin{array}{c}\text { OR } \\
(95 \% \mathrm{Cl}) \\
\end{array}$ \\
\hline Supraclinoid & & & .091 & $1.75(0.91-3.36)$ \\
\hline$\leq 15.40^{\circ}$ & $71(74.74)$ & $24(25.26)$ & & \\
\hline$>15.40^{\circ}$ & 49 (62.82) & $29(37.18)$ & & \\
\hline MCA & & & .354 & $1.32(0.73-2.40)$ \\
\hline$\leq 15.40^{\circ}$ & 83 (77.57) & $24(22.43)$ & & \\
\hline$>15.40^{\circ}$ & 94 (72.31) & $36(27.69)$ & & \\
\hline AcomA & & & .049 & $1.84(1.00-3.38)$ \\
\hline$\leq 15.40^{\circ}$ & 45 (55.56) & $36(59.55)$ & & \\
\hline$>15.40^{\circ}$ & $36(40.45)$ & $53(59.55)$ & & \\
\hline Bifurcation & & & .470 & $1.90(0.43-8.48)$ \\
\hline$\leq 15.40^{\circ}$ & 14 (77.78) & $4(22.22)$ & & \\
\hline$>15.40^{\circ}$ & 11 (64.71) & $6(35.29)$ & & \\
\hline
\end{tabular}

Note:- Supraclinoid indicates supraclinoid segments, including the ophthalmic, posterior communicating, and anterior choroidal segments; Bifurcation, internal carotid artery bifurcation; AcomA, anterior communicating artery.

\begin{tabular}{|c|c|c|c|c|}
\hline \multirow[b]{2}{*}{ Variables } & \multicolumn{2}{|c|}{$\begin{array}{c}\text { Crude OR } \\
\text { (Postsiphon/Siphon) }\end{array}$} & \multicolumn{2}{|c|}{$\begin{array}{c}\text { Adjusted OR } \\
\text { (Cavernous/Supraclinoid) }\end{array}$} \\
\hline & OR (95\% CI) & $P$ Value & OR $(95 \% \mathrm{Cl})$ & $P$ Value \\
\hline Sex & & $<.001$ & & .427 \\
\hline Male & $2.23(1.48-3.37)$ & $<.001$ & 0.69 (0.27-1.74) & .427 \\
\hline Female & 1 & - & 1 & - \\
\hline Age & & .184 & & .684 \\
\hline 55 yr or younger & 1.28 (0.89-1.84) & .184 & $1.16(0.57-2.38)$ & .684 \\
\hline Older than $55 \mathrm{yr}$ & 1 & - & 1 & - \\
\hline Rupture & & .423 & & \\
\hline No & 1 & - & & \\
\hline Yes & $1.17(0.80-1.72)$ & .423 & & \\
\hline \multicolumn{5}{|l|}{ Aneurysm size } \\
\hline$\leq 5 \mathrm{~mm}$ & $2.38(0.69-8.20)$ & .169 & $0.08(0.02-0.28)$ & $<.001$ \\
\hline $6-10 \mathrm{~mm}$ & $2.54(0.73-8.85)$ & .143 & $0.09(0.03-0.35)$ & $<.001$ \\
\hline $11-25$ mm & $1.34(0.37-4.81)$ & .652 & $0.12(0.03-0.45)$ & .002 \\
\hline$>25 \mathrm{~mm}$ & 1 & - & 1 & - \\
\hline Anterior knee angle & & .034 & & .066 \\
\hline$\leq 15.40^{\circ}$ & 1 & - & 1 & - \\
\hline$>15.40^{\circ}$ & $1.48(1.03-2.13)$ & .034 & $0.48(0.22-1.05)$ & .066 \\
\hline Posterior knee angle & & .122 & & .093 \\
\hline$\leq 88.15^{\circ}$ & 1 & - & 1 & - \\
\hline$>88.15^{\circ}$ & $1.33(0.93-1.91)$ & .122 & $1.84(0.90-3.73)$ & .093 \\
\hline
\end{tabular}

shear oscillations and lower wall shear stress. Changes in the direction of blood flow due to the curvature of the carotid siphon would be related to the transition from laminar to turbulent flow. These changes in blood flow patterns would lead to decreased and oscillating wall shear stress, thus triggering the first endothelial changes in the genesis of aneurysm and stenosis formation. ${ }^{4,5}$

Jou et al, ${ }^{16}$ using 3D images from 25 patients with paraclinoid aneurysms, reported that mean wall shear stress is inversely dependent on aneurysm sac size and that ruptured aneurysms have lower mean wall shear stress when they are close to the aneurysm neck. Zhang et al, ${ }^{17}$ also using 3D images, hemodynamic studies, and the anatomic classification in V, U, C, and S shape, showed that stenotic lesions tend to occur right after the sharp bends of the carotid siphon and that siphons with sharper bends, such as the type $\mathrm{C}$ shape, have statistically more stenoses than siphons with softer bends. Piccinelli et $\mathrm{al}^{18}$ individually analyzed the carotid siphon bends with aneurysms and showed that ruptured aneurysms occur statistically more often in carotid siphon bends of smaller diameter and shorter length, and along the outer wall of the curvature. In a recent study, Lauric et al, ${ }^{19}$ comparing demographic data and 3D DSA images, showed that women have carotid siphons with higher curvatures than men and that patients with siphons with aneurysms also have higher mean curvatures.

In the present study, we used a simple and reproducible method to analyze the sharpness of the 2 main curvatures through which blood enters the cerebral circulation-that is, the posterior and anterior knee angles of the carotid siphon, associated with a refined statistical analysis to identify independent variables resulting from angle variation. We first performed a $2 \mathrm{D}$ analysis of each variable, followed by several multivariate regression analyses to isolate, from all other potentially correlated factors, the consequences of the variation of these angles in relation to intracranial aneurysm rupture, location, and size.

We found that anterior angle values above the median of the study sample $\left(15.40^{\circ}\right)$ were directly and independently associated with a $36 \%$ higher incidence of ruptured aneurysms $(P=.005$, prevalence ratio $=1.36 ; 95 \%$ CI, 1.09-1.69), with a $48 \%$ greater chance of having an aneurysm in the postsiphon location $(P=.034$, OR $=$ 1.48; 95\% CI, 1.03-2.13), and with larger aneurysms, in which every $1^{\circ}$ increase in the anterior angle produced an increase of $1.001 \mathrm{~mm}$ in aneurysm size $(P=.015)$.

We believe that the change in the blood flow direction at the curvature points of the carotid siphon would occur by a deceleration of the linear velocity of blood flow and loss of the linear vector force of the water hammer pulse. This deceleration would occur with a change of laminar-to-turbulent flow in the vicinity of curvatures, with higher wall shear oscillations and lower wall shear stress. On the one hand, the decrease in the linear vector force toward the aneurys- 
Table 5: Results of multiple linear regression analysis in relation to aneurysm size

\begin{tabular}{lcc}
\hline $\begin{array}{l}\text { Variables Associated with } \\
\text { Larger Aneurysms }\end{array}$ & $\boldsymbol{P}$ Value & \multicolumn{1}{c}{$\mathbf{9 5 \%} \mathrm{Cl}$} \\
\hline $\begin{array}{l}\text { Aneurysm location } \\
\quad \text { Postsiphon/supraclinoid }\end{array}$ & .016 & $0.901-0.989$ \\
$\quad$ Cavernous/supraclinoid & $<.001$ & $1.133-1.350$ \\
Sex & & \\
$\quad$ Male/female & .103 & $0.993-1.081$ \\
Rupture & & \\
$\quad$ Yes/no & .026 & $0.913-0.994$ \\
$\quad$ Anterior knee angle & .015 & $1.000-1.002$ \\
$\quad$ Posterior knee angle & .804 & $1.000-1.000$ \\
Age & .003 & $1.000-1.003$ \\
\hline
\end{tabular}

mal sac would reduce the aneurysm size and risk of rupture; on the other hand, a greater turbulent flow would lead to a greater initial endothelial lesion for aneurysmal formations. Thus, more obtuse anterior angles with less laminar flow deceleration and less generation of turbulent flow in the vicinity of the carotid siphon were statistically associated with larger aneurysms, greater risk of rupture and a higher incidence of aneurysms distal to the carotid siphon. In turn, more acute anterior angles with greater deceleration of laminar flow and greater generation of turbulent flow in the siphon were shown to be associated with smaller aneurysms, a lower risk of rupture, and a higher incidence of aneurysms in the carotid siphon.

High-speed laminar flow due to a low tortuous carotid siphon would lead to hemodynamic effects for other circulation bends and bifurcations distal to the carotid siphon, explaining the higher incidence of postsiphon aneurysms and the greater risk of rupture in these locations in patients with higher anterior angles. The stratified analysis of subgroups by location revealed that aneurysms located in the anterior communicating artery in patients with an anterior angle of $>15.40^{\circ}$ had an $84 \%$ greater chance of rupture $(P=.049)$, suggesting that the hemodynamic effects resulting from carotid siphon anatomy persist distal to the siphon.

We also expected to observe a higher incidence of cavernous segment aneurysms in patients with more acute posterior angles. However, we did not observe any statistical relationship between the posterior angle measures and the studied variables. When comparing the values of anterior and posterior angles, we observed that posterior angle measures were more homogeneous, with a lower SD $\left(14.63^{\circ} \pm\right.$ $26.13^{\circ}$ versus $83.37^{\circ} \pm 37.54^{\circ}$ ), and perhaps this lower variability was the reason for the lack of a statistical relationship using our method. In addition, other anatomic obstacles could be related to cavernous aneurysm genesis, such as the angles of the petrous segment, which unfortunately are not the focus of our study.

A relevant finding was the independent statistical relationship between aneurysm size and patient age, in which every 1-year increase in age produced an average increase of $1.002 \mathrm{~mm}$ in aneurysm size.

As a partially retrospective review, this study has some limitations related to the quality of the data collected from the available medical records. However, the use of 2 blinded assessors for angle measurement and a large sample were contributing factors to improve the level of information.

\section{CONCLUSIONS}

There was a significant independent direct relation of greater anterior knee angle with intracranial aneurysms located distal to the carotid siphon, larger aneurysms, and greater risk of rupture. These findings may be associated with the hemodynamic interactions of blood flow and the curvature of the carotid siphon.

\section{REFERENCES}

1. Caranci F, Briganti F, Cirillo L, et al. Epidemiology and genetics of intracranial aneurysms. Eur J Radiol 2013;82:1598-605 CrossRef Medline

2. King JT Jr. Epidemiology of aneurysmal subarachnoid hemorrhage. Neuroimaging Clin N Am 1997;7:659-68 Medline

3. Takeuchi S, Karino T. Flow patterns and distributions of fluid velocity and wall shear stress in the human internal carotid and middle cerebral arteries. World Neurosurg 2010;73:174-85; discussion e27 CrossRef Medline

4. Sforza DM, Putman CM, Cebral JR. Hemodynamics of cerebral aneurysms. Annu Rev Fluid Mech 2009;41:91-107 CrossRef Medline

5. Malek AM, Alper SL, Izumo S. Hemodynamic shear stress and its role in atherosclerosis. JAMA 1999;282:2035-42 CrossRef Medline

6. Naruse T, Tanishita K. Large curvature effect on pulsatile entrance flow in a curved tube: model experiment simulating blood flow in an aortic arch. J Biomech Eng 1996;118:180-86 CrossRef Medline

7. Griessenauer CJ, Yalcin B, Matusz P, et al. Analysis of the tortuosity of the internal carotid artery in the cavernous sinus. Childs Nerv Syst 2015;31:941-44 CrossRef Medline

8. Lin LM, Colby GP, Jiang B, et al. Classification of cavernous internal carotid artery tortuosity: a predictor of procedural complexity in Pipeline embolization. J Neurointerv Surg 2015;7: 628-33 CrossRef Medline

9. Bogunović H, Pozo JM, Cárdenes R, et al. Automated landmarking and geometric characterization of the carotid siphon. Med Image Anal 2012;16:889-903 CrossRef Medline

10. Silva Neto ÂR, Câmara RL, Valença MM. Carotid siphon geometry and variants of the circle of Willis in the origin of carotid aneurysms. Arq Neuropsiquiatr 2012;70:917-21 CrossRef Medline

11. Barros AJ, Hirakata VN. Alternatives for logistic regression in crosssectional studies: an empirical comparison of models that directly estimate the prevalence ratio. BMC Med Res Methodol 2003;3:21 CrossRef Medline

12. Allison PD. Binary logit analysis: details and options. In: Logistic Regression Using SAS: Theory and Application. 2nd ed. Cary: SAS Institute; 1999:48-51

13. Hosmer DW, Lemeshow S. Special topics. In: Applied Logistic Regression. 2nd ed. Hoboken: John Wiley \& Sons; 2000:260-73

14. Brisman JL, Song JK, Newell DW. Cerebral aneurysms. N Engl J Med 2006;355:928-39 CrossRef Medline

15. Thomas JB, Antiga L, Che SL, et al. Variation in the carotid bifurcation geometry of young versus older adults: implications for geometric risk of atherosclerosis. Stroke 2005;36:2450-56 CrossRef Medline

16. Jou LD, Lee DH, Morsi $\mathrm{H}$, et al. Wall shear stress on ruptured and unruptured intracranial aneurysms at the internal carotid artery. AJNR Am J Neuroradiol 2008;29:1761-67 CrossRef Medline

17. Zhang C, Pu F, Li S, et al. Geometric classification of the carotid siphon: association between geometry and stenoses. Surg Radiol Anat 2013;35:385-94 CrossRef Medline

18. Piccinelli M, Bacigaluppi S, Boccardi E, et al. Geometry of the internal carotid artery and recurrent patterns in location, orientation, and rupture status of lateral aneurysms: an image-based computational study. Neurosurgery 2011;68:1270-85; discussion 1285 CrossRef

19. Lauric A, Safain MG, Hippelheuser J, et al. High curvature of the internal carotid artery is associated with the presence of intracranial aneurysms. J Neurointerv Surg 2014;6:733-39 CrossRef Medline 